Цитування на цю статтю:

Заборняк С, Кухцяк М, Мицкан БМ, Мицкан ТС. Фізична культура в українських школах Галичини (1868-1918 рр.) Вісник Прикарпатського університету. Серія: Фізична культура. 2020 Листоп 03; 35: 34-42

\begin{tabular}{|c|c|}
\hline Відомості про автора: & Information about the author: \\
\hline $\begin{array}{l}\text { Заборняк Станіслав - доктор габілітований } 3 \\
\text { фізичної культури, професор, Жешувський універ- } \\
\text { ситет (Жешув, Польща) }\end{array}$ & $\begin{array}{l}\text { Zabornyak Stanislav - Doctor habilitowany of } \\
\text { Science of Physical Education and Sport, Professor, } \\
\text { University of Rzeszów (Rzeszów, Poland) }\end{array}$ \\
\hline \multicolumn{2}{|l|}{ e-mail: zaborniaks@wp.pl } \\
\hline $\begin{array}{l}\text { Мицкан Богдан Михайлович - доктор біологічних } \\
\text { наук, професор, завідувач кафедри теорії та мето- } \\
\text { дики фізичної культури і спорту, ДВНЗ "Прикар- } \\
\text { патський національний університет імені Василя } \\
\text { Стефаника" (Івано-Франківськ, Україна) }\end{array}$ & $\begin{array}{l}\text { Mytskan Bohdan Mykhailovych - Doctor of Bio- } \\
\text { logical Science, Professor, Head of Chair of Theory } \\
\text { and Methods of Physical Training and Sports, Vasyl } \\
\text { Stefanyk Precarpathian National University (Ivano- } \\
\text { Frankivsk, Ukraina) }\end{array}$ \\
\hline \multicolumn{2}{|l|}{$\begin{array}{l}\text { e-mail: bogdanmytskan21@gmail.com } \\
\text { https://orsid.org/0000-0002-5853-713X }\end{array}$} \\
\hline $\begin{array}{l}\text { Мицкан Temяна Cmenaнiвна - кандидат психо- } \\
\text { логічних наук, доцент, ДВНЗ “Прикарпатський на- } \\
\text { ціональний університет імені Василя Стефаника" } \\
\text { (Івано-Франківськ, Україна) }\end{array}$ & $\begin{array}{l}\text { Mytskan Tetiana Stepanivna - Candidate of Science } \\
\text { (Psychology), Associate Professor (Ph. D.), Vasyl } \\
\text { Stefanyk Precarpathian National University (Ivano- } \\
\text { Frankivsk, Ukraine) }\end{array}$ \\
\hline
\end{tabular}

УДК 796.81.052.242

doi: 10.15330/fcult.35.42-48

\section{Віталій Кашуба, Владислав Данильченко, Ілля Вако, Олександр Кримець}

\title{
З ДОСВІДУ ВИКОРИСТАННЯ КВАЛИМЕТРІЇ ЩОДО ІДЕНТИФІКАЦІЇ РУХОВИХ ПОМИЛОК ПРИ ФОРМУВАННІ ТЕХНІКИ РУКОПАШНОГО БОЮ
}

Мета. Визначити орієнтири підвищення ефективності процесу формування техніки рукопашного бою. Методи. Для досягнення поставленої мети було використано такі методи дослідження: аналіз науково-методичної літератури та документальних матеріалів, кваліметрія - метод експертних оиінок. При проведенні експертизи методом надання переваги розрахункове значення коефіцієнта конкордації $W$ становило 0,92 (p<0,05), тобто результатам проведеної експертизи можна довіряти, саму експертизу можна вважати такою, ще відбулася, а думку експертів - узгодженою. Експертну оцінку проводили за участю 26-ти фахівців. Результати. У процесі досліджень нами визначена ступінь узгодженості думок експертів при ранжируванні типових помилок, які допускають курсанти при освоєнні больових $i$ задушливих прийомів в прочесі спеціальної фізичної підготовки. Отримані дані дозволяють припустити, щзо подолання технічних помилок - одна з найважливіших завдань процесу спеціальної фізичної підготовки. Багато помилок, які допускають курсанти при освоєнні больових $і$ задушливих прийомів пов'язані 3 руховими помилками. Відповідно до сучасних уявлень рухова неточність - невід'ємний компонент рухової діяльності. Важливо відзначити, щэо рухові помилки - це не тільки значущі неточності. Спортсмен може просто недостатньо добре знати, як формується та чи інша рухова дія, щзо буває результатом помилокщзодо техніки вправи і техніки його виконання, результатом нездатності (тим більше в умовах дефіциту часу) знайти доиільний варіант техніки вправи для створення особливих (відрізняються від звичних) умов його виконання, у результаті невміння, забезпечити правильне виконання вправи з-за недостатнього рухового потенціалу, в тому числі в зв'язку з втомою. Висновок. Визначено орієнтири підвищення ефективності прочесу формування базової техніки рукопашного бою.

Ключові слова: техніка рукопашного бою, кваліметрія, рухові помилки.

The purpose of the study is to determine the guidelines for efficiency improving of hand combat techniques formation process. In the special literature it is observed that the failure is a kind of exercise performing with a deviation from technique model, which has a significant impact on the action result. The main failures are failures that distort the main movement mechanism, additional failures distort the technique details. Objectives of the study: based on the expert assessments method using, to identify perspectives for efficiency improving of forming process of the basic hand combat technique. Results. In the research there were determined the consistency degree of experts' opinions in ranking the typical failures that cadets make while 
mastering painful and stifling techniques in special physical training process. The obtained data suggest that technical failures overcoming is one of the most important tasks of special physical training process. A lot of failures that cadets make while mastering painful and stifling techniques are connected with motor imprecisions. According to modern ideas, motor imprecision is an integral component of motor activity. It is important to note that motor failures are not only significant imprecisions. The athlete may be not acquainted enough with some motor action forming, that results in its failure, as for exercise technique and performance technique, the result of inability (especially in lack time conditions) to find a suitable exercise technique to create special (that differs from usual) conditions of its implementation, as a result of ineptitude to provide proper exercise performance due to insufficient motor potential, including fatigue. The guidelines for efficiency increasing of basic hand combat technique forming process have been determined. Conclusijn. Prospects for further research will be related to the concept development of basic hand combat technique forming in young athletes.

Keywords: hand combat technique, qualimetry, motor, failures.

Постановка проблеми й аналіз результатів останніх досліджень. У спеціальній літературі зазначається, що помилка - це виконання вправи з відхиленням від моделі техніки, яке надає відчутний вплив на результат дії $[7,13]$. Як відзначають фахівці $[7,13]$ не всяке відхилення встановленого способу має розглядатися як помилка. Нерідко відхилення $є$ не чим іншим як індивідуальними особливостями виконання вправи $[7,13]$. Тренеру-викладачу бути обережним, щоб не прийняти ці відхилення за помилки, особливо якщо учні неухильно просуваються вперед і мають високий спортивнотехнічний рівень підготовки [13].

Коренберг В.Б. у своїй роботі [13] вказує, що головні помилки - це ті, які спотворюють основний механізм руху, другорядні помилки - спотворюють деталі техніки.

Згідно з наявними уявленнями [15] помилки діляться на технічні, тактичні та фонові. Технічні пов'язані зі структурою рухової дії, тактичні - зі смисловою стороною дії. Фонові помилки, як правило, мають естетичне значення: помилки пози, помилки ритму, помилки пересувань [15].

Слід також зазначити, що помилки можуть бути звичні і випадкові. Вельми важливо відзначити, що помилки зустрічаються як в окремих рухових діях, так і загальних $[1,12,15]$. В процесі тренування, перш за все, слід позбавлятися технічних помилок, потім від тактичних і насамкінець усувати фонові $[11,15]$.

Мета дослідження - визначити орієнтири підвищення ефективності процесу формування техніки рукопашного бою.

Методи дослідження. Для досягнення поставленої мети було використано такі методи дослідження: аналіз науково-методичної літератури та документальних матеріалів, кваліметрія - метод експертних оцінок. При проведенні експертизи методом надання переваги розрахункове значення коефіцієнта конкордації $\mathrm{W}$ становило 0,92 (p<0,05), тобто результатам проведеної експертизи можна довіряти, саму експертизу можна вважати такою, що відбулася, а думку експертів - узгодженою. Експертну оцінку проводили за участю 26-ти фахівців.

Результати дослідження. Ми враховували рекомендації [13] в яких вказується, що слід розрізняти кілька градацій усвідомлення рухової помилки: 1) констатація ії наявності, 2) iї виявлення (констатація наявності з визначенням "пошкодженого місця" системи рухів), 3) розпізнавання (ідентифікація), 4 ) аналітичне визначення, 5) аналітична оцінка.

Ступінь узгодженості думок експертів при ранжируванні типових помилок, які допускають курсанти при освоєнні больових і задушливих прийомів в процесі спеціальної фізичної підготовки [13] представлена в табл. 1. Отримані дані дозволяють припустити, що подолання технічних помилок - одна 3 найважливіших завдань процесу спеціальної фізичної підготовки [13].

На нашу думку, багато помилок, які допускають курсанти при освоєнні больові i задушливі прийомів пов'язані з руховими неточностями. Відповідно до сучасних уявлень 
рухова неточність - невід'ємний компонент рухової діяльності $[1,2,4,13]$. Водночас, наявні дані переконують, що вони повинні досягати якоїсь істотної величини, щоб можна було їх помітити, відзначити небажане відхилення результату дії від запрограмованого і таким чином констатувати наявність рухової помилки. Таким чином, відповідно до сучасних рекомендацій фахівців $[3,11,12,13]$ руховими помилками слід називати лише такі рухові неточності, які тягнуть за собою відчутне погіршення техніки рухової дій.

Ступінь узгодженості думок експертів при ранжируванні типових помилок, які допускають курсанти при освоснні больових і задушливих прийомів в процесі спеціальної фізичної підготовки (n=26)

\begin{tabular}{|c|l|c|}
\hline № 3/п & \multicolumn{1}{|c|}{ Прийом } & $\begin{array}{c}\text { Коефіцієнт } \\
\text { конкордації }\end{array}$ \\
\hline 1. & Больовий прийом “Загинання руки за спину способом “замком” & 0,92 \\
\hline 2. & Больовий прийом “Важіль руки назовні” & 0,81 \\
\hline 3. & Больовий прийом “Загинання руки за спину способом “ривком” & 0,85 \\
\hline 4. & Больовий прийом “Загинання руки за спину замком” & 0,90 \\
\hline 5. & Больовий прийом “Важіль руки всередину” & 0,86 \\
\hline 6. & $\begin{array}{l}\text { Больовий прийом “Важіль руки через передпліччя при підході } \\
\text { збоку” }\end{array}$ & 0,92 \\
\hline 7. & Больовий прийом “Важіль руки через шию при підході збоку” & 0,92 \\
\hline 8. & $\begin{array}{l}\text { Больовий прийом “Загинання руки за спину при підході спереду і } \\
\text { ззаду” }\end{array}$ & 0,86 \\
\hline 9. & Больовий прийом з дожином на лучезап’ястний суглоб & 0,81 \\
\hline 10. & Больовий прийом на ногу, защемлення ахіллового сухожилля & 0,86 \\
\hline 11. & Больовий прийом важіль ліктя через стегно & 0,84 \\
\hline 12. & Больовий прийом вузол плеча ногою & 0,88 \\
\hline 13. & Задушливий прийом плечем і передпліччям & 0,84 \\
\hline 14. & Задушливий прийом подвійним захоплення & 0,91 \\
\hline
\end{tabular}

Сучасні уявлення фахівців $[7,13,14,16]$, що займаються проблемами рухових помилок при формуванні техніки рухових дій зводяться до того, що в основі походження рухової неточності лежить ряд детермінант (рис. 1).

Дискусія. Важливо відзначити, що рухові помилки - це не тільки значущі неточності $[5,13]$. Спортсмен може просто недостатньо добре знати, як формується та чи інша рухова дія, що буває результатом помилок - щодо техніки вправи і техніки його виконання, результатом нездатності (тим більше в умовах дефіциту часу) знайти раціональний варіант техніки вправи для створення особливих (відрізняються від звичних) умов його виконання, забезпечити правильне виконання вправи із-за недостатнього рухового потенціалу, в тому числі обумовленого стомленням.

Звертає на себе увагу, що руховим помилкам часто властива “багатоповерховість”: одна тягне за собою іншу, створюючи причинно-наслідковий ланцюг [13].

Як зазначається в роботі [13], про незалежність рухової помилки якогось одного типу від помилок всіх інших типів можна говорити тільки в окремому випадку або дуже умовно, оскільки всі визначальні їх чинники найтіснішим чином пов'язані: напруга скелетних м'язів і динамічна взаємодія з іншими тілами залежать від пози, швидкості рухів, їх ритму; прискорення і швидкість рухів залежать від напруги м'язів і динамічних взаємодій з іншими тілами, від пози (плече сили тяги м'яза - показник змінний, що залежить від взаємного розташування ланок в суглобі), ритму руху та м'язових напружень. Ритм і геометрія рухів ще більш явно залежать один від одного та від кінематики і динаміки дій [8]. 
1

• коливання напруги навколо цього значення (тремор м'язів), які можна зменшшити тренуванням, але яких не можна уникнути, вже забезпечують якусь рухову неточність

\section{2}

- напруга м'язів, що може пояснюватися хоча б тією обставиною, що фізіологічний стан нервової і м'язової систем не постійно, воно весь час в якійсь мірі змінюється, так що одна $і$ та ж кодова програма викликає кожен раз трохи розрізняються між собою напруги. Ця неточність вловлюється пропріорецепторамп, і в напруження вносяться корекціі

3

- в результаті неточностей в напрузі м'язів рухи відбуваються в дещо іншшх, ніж було запрограмовано, напрямках і $з$ трохи іншшм прискоренням (а звідси і швидкістю) - у наявності неточності в кінематичній структурі рухової дії

Puc. 1. Детермінанти, що лежать в основі походження рухових неточностей $[7,13,14,16]$.

Дуже істотним на наш погляд є те, що “багатоповерховість” (причинна ієрархія) рухових помилок - одна з головних труднощів при їх аналізі з метою усунення [13].

Дослідженнями $[6,7,8]$ встановлено, що група помилок через проблеми навчання ділиться теж на чотири підгрупи (рис. 2).

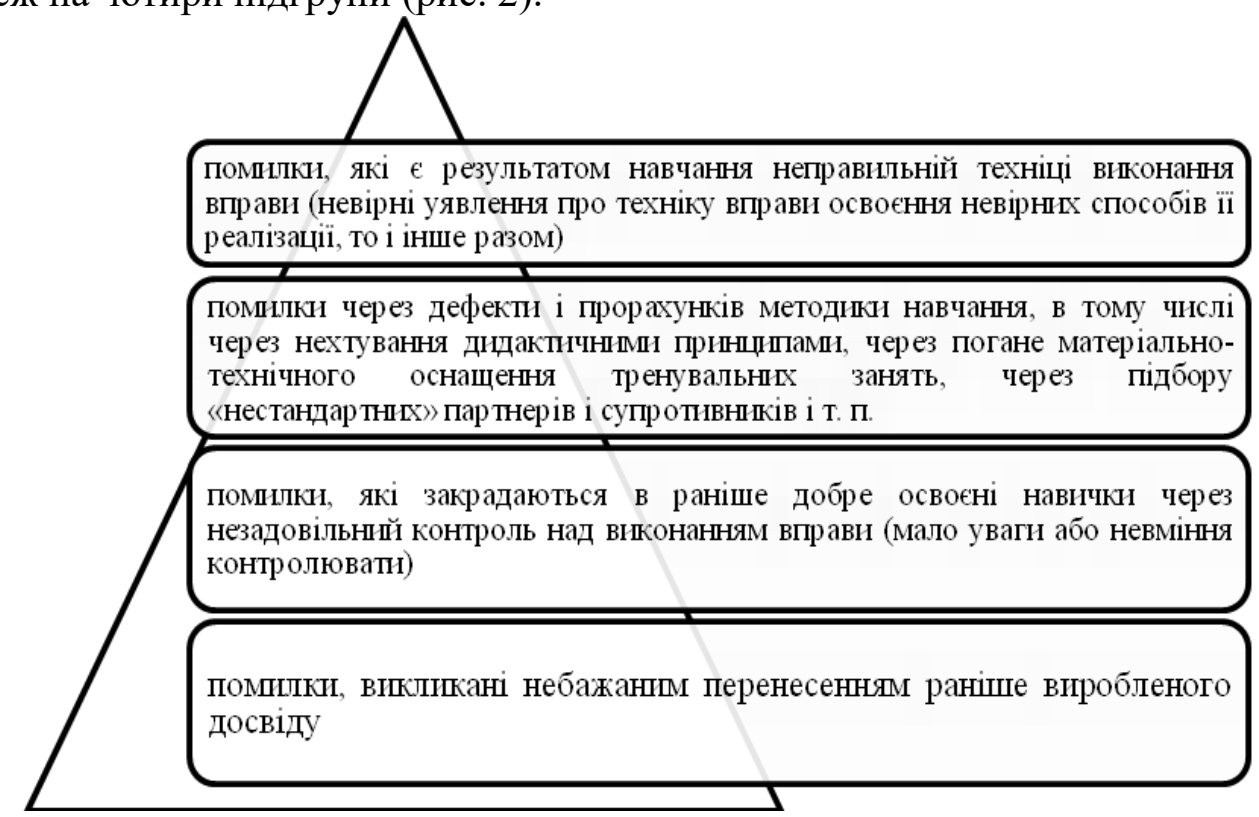

Puc. 2. Класифікація помилок, пов’язаних з проблемами навчання $[6,7,13]$.

Висновок. Отже, група помилок через проблеми навчання ділиться на чотири підгрупи: помилки, які є результатом навчання неправильній техніці виконання вправи (невірні уявлення про техніку вправи, освоєння хибних способів іiі реалізації); помилки, які закрадаються в раніше добре освоєні навики через незадовільний контроль над ви- 
конанням вправи (мало уваги або невміння контролювати рухові дії); помилки, викликані небажаним перенесенням раніше виробленого досвіду; помилки через прорахунки методики навчання, в тому числі через нехтування дидактичними принципами, через погане матеріально-технічного оснащення тренувальних занять, через добір “нестандартних" партнерів і супротивників тощо; помилки, викликані небажаним перенесенням раніше виробленого досвіду.

1. Вако I. Систематизація сучасних методик навчання прийомам рукопашного бою Вісник Чернігівського національного педагогічного університету. Серія: Педагогічні науки. Фізичне виховання та спорт. 2012; 102 (1): 104-106.

2. Вако І. Кількісна біомеханічна характеристика базової техніки рукопашного бою курсантів у процесі спеціальної фізичної підготовки. Молодіжний науковий вісник Східноєвропейського національного університету імені Лесі Українки. 2015; 17: 33-38.

3. Вако I. Особливості використання прийомів рукопашного бою в умовах оперативних дій співробітниками спеціальних служб. Теорія і методика фізичного виховання і спорту. 2015; 3: $42-47$.

4. Вако I. Особливості техніки рукопашного бою у процесі спеціальної фізичної підготовки курсантів Науковий часопис Національного педагогічного університету імені М. П. Драгоманова (Сер. № 15: Науково-педагогічні проблеми фізичної культури / Фізична культура і спорт) / за ред. Г. М. Арзютова. К. : НПУ імені М. П. Драгоманова, 2015; 6 (62): 17-20.

5. Вако І. Технологія удосконалення техніки рукопашного бою майбутніх спеціалістів Служби безпеки України Молодіжний науковий вісник Східноєвропейського національного університету імені Лесі Українки. 2015; 19: 37-42.

6. Данильченко В, Вако И. Технология формирования базовой техники рукопашного боя у курсантов в процессе специальной физической підготовки. Молодіжний науковий вісник Східноєвропейського національного університету імені Лесі Українки. 2014; 16: 52-56.

7. Данильченко В. Формування техніки рукопашного бою в процесі спеціальної фізичної підготовки курсантів вищих навчальних закладів МВС України: автореф. ... канд. наук з фізичного виховання та спорту. 24.00.02 . Київ, 2015. 24 с.

8. Кашуба ВА, Литвиненко ЮВ, Данильченко ВА. Моделирование движений в спортивной тренировке. Физическое воспитание студентов. 2010;(4):40-4.

9. Кашуба ВА, Литвиненко ЮВ, Зарудный ВЮ, Беленко СС. Биомеханические аспекты техники ударных действий в восточных единоборствах. Теория и методика физической культуры. 2012; 4(31): 90-96.

10. Кашуба ВА, Литвиненко ЮВ, Юхно ЮА, Зарудний ВЮ, Беленко СС. Теоретико-практические аспекты использования оптико-электронных систем регистрации движений при биомеханическом анализе спортивной техники. Молодіжний науковий вісник Східноєвроп. нац. ун-ту ім. Лесі Українки. 2013; (9): 7-15.

11. Кашуба ВА, Литвиненко ЮВ, Гордеева МВ, Зарудный ВЮ. Биомеханика спортивных движений и современные видеокомпьютерные методы их контроля. Теория и методика физической культуры. 2013; 4(35): 31-37.

12. Кашуба ВА, Гордеева МВ, Жук АА, Ризатдинова АС, Литвиненко ЮВ. Программа повышения эффективности техники двигательных действий в видах спорта со сложнокоординационной структурой движения. B: Știinţa culturii fizice. Revistă teoretico-știinţifică. Chisinau: Universitatea de Stat de Educaţie Fizică și Sport, Publicaţie știinţifi că recenzată (Categoria “C”); 2017; 27 (1): 93-98.

13. Коренберг В.Б. Основы качественного биомеханического анализа / Коренберг В.Б. М.: Физкультура и спорт, 1979. 208 с.

14. Литвиненко ЮВ, Беленко СС. Біомеханічні особливості техніки ударних дій в тайському боксі спортсменами різної кваліфікації. Теорія і методика фізичного виховання і спорту. 2013;(2):118-121.

15. Теория и методика физического воспитания: учебник для студентов вузов физ. воспит. и спорта: Т 2. Общие основы теории и методики физического воспитания /под ред. Т.Ю. Круцевич. К., 2008. 392 с.

16. Gamaliy V, Kashuba V, Lytvynenko Y, Zhezhel E. Coordination of muscle exertions as part of individual's motive actions technique. Coordination motor abilities in scientific research. Biala Podlaska. 2008; (24): 283-7.

\section{References}

1. Wako I. Systematization of modern methods of training in hand-to-hand combat. Bulletin of the Chernigiv National Pedagogical University (Ser .: Pedagogical Sciences. Physical education and sport) / Chernigiv. nat. ped. un-t im. T. G. Shevchenko. Chernigiv, 2012; 102 (1): 104-106. 
2. Wako I. Kilkisna biomechanical characteristic of the basic technique of hand-to-hand combat of cadets in the process of special physical training. Young Science Newsletter of the European National University of Ukraine for Men of Forest. 2015; 17: 33-38.

3. Wako I. Special features of training in hand-to-hand combat in the minds of operative athletes of special services. Theory and technique of physical training and sports. 2015; 3: 42-47.

4. Wako I. Special features of hand-to-hand combat techniques in the process of special physical training of cadets Science hour writing of the National Pedagogical University named after M. P. Dragomanov (Ser. No. 15: Scientific and pedagogical problems of physical culture / physical sports) for culture. G.M. Arzyutova. K.: NPU imene M.P. Dragomanova. 2015; 6 (62): 17-20.

5. Wako I. Technology for improving the technique of hand-to-hand combat of the Maybut specials of the Security Service of Ukraine. Young Science Newsletter of the European National University of the Ukrainian Forest. 2015; 19: 37-42.

6. Danilchenko V. Vako I. Technology of formation of the basic technique of hand-to-hand combat among cadets in the process of special physical training. Young Science Visnik of the European National University of Ukraine.2014; 16: 52-56.

7. Danilchenko V. Formation of hand-to-hand combat equipment in the process of special physical training of cadets of higher educational institutions of the Ministry of Internal Affairs of Ukraine: author's ref. .... candidate of iciences in Physical Education and Sports. 24.00.02. Kyiv, 2015. 24 p.

8. Kashuba VA, Litvinenko YV, Danilchenko VA. Simulation of movements in sports training. Physical education of students. 2010; (4): 40-4.

9. Kashuba VA, Litvinenko YV, Zarudny VYu, Belenko SS. Biomechanical aspects of percussion technique in martial arts. Theory and methodology of physical culture. 2012; 4 (31): 90-6.

10. Kashuba VA, Litvinenko YV, Yukhno YA, Zarudny VY, Belenko SS. Theoretical and practical aspects of the use of optical-electronic systems for registration of movements in biomechanical analysis of sports equipment. Young Science Visnik Skhidnoevrop. nat. un-tu im. Lesi Ukrainka. 2013; (9): 7-15.

11. Kashuba VA, Litvinenko YuV, Gordeeva MV, Zarudny VYu. Biomechanics of sports movements and modern video-computer methods of their control. Theory and methodology of physical culture. 2013; 4(35): 31-37.

12. Kashuba VA, Gordeeva MV, Zhuk AA, Rizatdinova AS, Litvinenko YuV. The program for improving the efficiency of motor actions technique in sports with a complex coordination structure of movement. In: Ştiinţa culturii fizice. Revistă teoretico-știinţifică. Chisinau: Universitatea de Stat de Educaţie Fizică și Sport, Publicaţie știinţifi că recenzată (Categoria “'C"). 2017; 27(1): 93-98.

13. Korenberg VB. Fundamentals of Qualitative Biomechanical Analysis. M.: Physical culture and sport, 1979. 208 p.

14. Litvinenko YV, Belenko SS. Biomechanical specialties of drumming technology in Thai boxing by athletes of excellent quality. Theory and methodology of physical education and sports. 2013; (2): 118-21.

15. Theory and methodology of physical education: textbook for university students fiz. educated and sport: T 2. General foundations of the theory and methods of physical education / T.Yu. Krucevich. K., 2008. $392 \mathrm{p}$.

16. Gamaliy V, Kashuba V, Lytvynenko Y, Zhezhel E. Coordination of muscle exertions as part of individual's motive actions technique. Coordination motor abilities in scientific research. Biala Podlaska. 2008; (24): $283-7$.

\section{Цитування на цю статтю:}

Кашуба ВО, Данильченко В, Вако I, Кримець О. 3 досвіду використання квалиметрії щодо ідентифікації рухових помилок при формуванні техніки рукопашного бою. Вісник Прикарпатського університету. Серія: Фізична культура. 2020 Листоп 03; 35: 42-48

\begin{tabular}{l|l} 
Відомості про автора: & Information about the author: \\
\hline $\begin{array}{l}\text { Кашуба Віталій Олександрович-доктор наук } 3 \\
\text { фізичного виховання та спорту, професор, Націо- } \\
\text { нальний університет фізичного виховання і спорту }\end{array}$ & $\begin{array}{l}\text { Kashuba Vitaliy Oleksandrovych - Doctor of Science } \\
\text { of Physical Education and Sport, Professor, National } \\
\text { University of Ukraine on Physical Education and Sport } \\
\text { (Kyiv, Ukraina) }\end{array}$ \\
\hline України (Київ, Україна) & \\
\hline e-mail: Vitaliy_kashuba@ukr.net \\
https://orcid.org/ 0000-0001-6669-738X
\end{tabular}


Вако Ілля - доцент кафедри олімпійського i професійного спорту, Чорноморський національний університет ім. Петра Могили (Миколаїв, Україна)

https://orcid.org/0000-0002-0541-5761

Кримець Олександр - старший викладач кафедри спеціальної фізичної підготовки, Національна академія внутрішніх справ (Київ, Україна) https://orcid.org/0000-0002-1950-0561
Vako Ilya - Associate Professor of Olympic and Professional Sports, Petro Mohyla Black Sea National University (Mykolaiv, Ukraine)

\section{УДК 373.016: 796(477) doi: 10.15330/fcult.35.48-59}

Олександр Лемак, Олександр Корсак, Ірина Султанова, Ірина Іванишин, Родіон Арламовський, Анна Фірка

\title{
ОСОБЛИВОСТІ ФІЗИЧНОГО СТАНУ ПІДЛІТКІВ З РІЗНИМ РІВНЕМ ФІЗИЧНОГО РОЗВИТКУ
}

\begin{abstract}
Мета. Дослідити взаємозв'язок між фізичним розвитком (на прикладі довжини тіла) $i$ фізичним станом в учнів підліткового віку. Методи. В дослідженні взяло участь 411 підлітків, з них 201 жіночої та 210 чоловічої статі. 3 метою вивчення особливостей фізичного стану досліджуваного контингенту (темпів росту) були використані такі методи: оцінка фізичної підготовленості школярів; визначення аеробної продуктивності методом степ-ергометрії; стан регуляторних механізмів оиінювали на підставі адаптаціийного потениіалу за М. Баєвським. У якості критерію фізичного розвитку використовували показники довжини тіла. Кількісні дані опрацьовані статистично з використанням методів варіаційної статистики та методів перевірки гіпотез. Результати. У підлітків жіночої статі в групі з низьким рівнем фізичного розвитку сприятливим періодом для розвитку гнучкості є вік 12-13 років, для розвитку швидкісно-силових здібностей - 13-14 років. У групі з середнім рівнем фізичного розвитку вік 13-14 років є сприятливим для розвитку динамічної сили згиначів плеча. Для розвитку швидкісно-силових здібностей період 13-14 років є сприятливим у підлітків чоловічої статі з високим та середнім рівнями фізичного розвитку; вік 13-15 років є сприятливим для групи підлітків з низьким рівнем фізичного розвитку. Динамічну силу згиначів плеча доиільно розвивати у 1314 років у підлітків з високим рівнем фізичного розвитку та у 15-16 років у групі з середнім рівнем фізичного розвитку. Для розвитку статичної м'язової витривалості сприятливим є період 13-14 років у підлітків з середнім рівнем фізичного розвитку. Висновок. Наявність сприятливих періодів для розвитку фізичних якостей у різні періоди онтогенезу та флюктуацій напруги адаптаційних механізмів у підлітків з різним рівнем фізичного розвитку, а також тендениії до зниження фізичної підготовленості та аеробної продуктивності зумовлює необхідність розробки та запровадження у практику їх фізичної підготовки диференційованих підходів з урахуванням рівня фізичного розвитку.
\end{abstract}

Ключові слова: фізичний стан, підлітки, фізичний розвиток, аеробна продуктивність, адаптаичійний потенцііал.

Investigate physical state of adolescents with different physical development levels of Precarpathian region. Material and methods of research. The study involved 411 adolescents, including 201 females and 210 males. In order to study physical status peculiarities of the studied contingent depending on physical development (growth rate), the following methods were used: students physical fitness assessment; aerobic productivity was measured via step ergometry method; regulatory mechanisms state was assessed on the basis of adaptation potential. Physical development level was assessed on the basis of body length anthropometric measurements. Study results are statistically processed using variation statistics and hypothesis testing method. Results. In female adolescents with low physical development level the most conducive period for flexibility development is 12-13 years, for speed and strength development is 13-14 years. In group with an average physical development level 13-14 years is the most conducive for development of shoulder flexors dynamic strength. For speed and strength abilities development, the period of 13-14 years is observed as the most conducive for male adolescents with high and medium physical development levels; 13-15 years is the most conducive for adolescents group with low physical development level. It is expedient to develop the shoulder flexors dynamic strength at the age of 13-14 in adolescents with a high physical development level and at the age of 15-16 in medium physical development level group. The period of 13-14 years in adolescents with an average physical development level is conducive for static muscular endurance development. Conclusion. The

(c) Лемак О., Корсак О., Султанова I.,

Іванишин I., Арламовський Р., Фірка А., 2020 